\title{
Urgences
}

\section{Laurent Dubé, Damnée Aimée, Montréal, VLB éditeur, 1983.}

\section{Françoise Daigle}

Numéro 10, 2e trimestre 1984

Spécial fantasmes

URI : https://id.erudit.org/iderudit/025164ar

DOI : https://doi.org/10.7202/025164ar

Aller au sommaire du numéro

Éditeur(s)

Urgences

ISSN

0226-9554 (imprimé)

1927-3924 (numérique)

Découvrir la revue

Citer ce compte rendu

Daigle, F. (1984). Compte rendu de [Laurent Dubé, Damnée Aimée, Montréal, VLB éditeur, 1983.] Urgences, (10), 121-124. https://doi.org/10.7202/025164ar

Ce document est protégé par la loi sur le droit d'auteur. L’utilisation des services d'Érudit (y compris la reproduction) est assujettie à sa politique d'utilisation que vous pouvez consulter en ligne.

https://apropos.erudit.org/fr/usagers/politique-dutilisation/
Cet article est diffusé et préservé par Érudit.

Érudit est un consortium interuniversitaire sans but lucratif composé de l'Université de Montréal, l'Université Laval et l'Université du Québec à Montréal. Il a pour mission la promotion et la valorisation de la recherche. https://www.erudit.org/fr/ 
DAMNÉE AIMÉE, de Laurent Dubé, VLB Éditeur, 1983.

Tous ceux qui voyagent de Québec à Rimouski connaissent fort bien la sainte litanie toponymique des villages qui s'égrènent le long du fleuve, de Saint-David à Saint-Fabien par Saint-Jean-Port-Joli et Saint-Simon, et comme j'en passe!

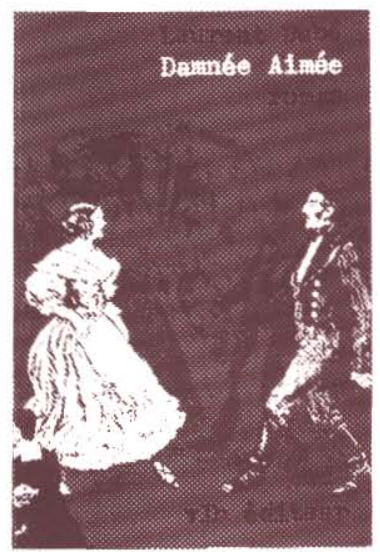

Mais sans doute connaissez-vous aussi, pour y avoir un "mononcle" ou une "matante", ces petits villages aux noms tout aussi pittoresques, juchés, si vous me permettez l'antithèse, sur les hautes terres du Bas-du-Fleuve: Saint-Jean-deDieu, Saint-Clément, Saint-Épiphane, Saint-Paul-de-la-Croix... Votre grand-père $y$ demeure, votre mère en est originaire: vous vous rappelez les "visites" à la parenté de votre enfance, la place de l'église épiée par les commères, le curé bedonnant et son maigre vicaire, le magasin général, la vieille cabane bâtie par les enfants derrière le cimetière paroissial...

C'est dans ce petit monde familier que Laurent Dubé nous amène, au tournant de notre époque, quelque part entre 1945 et plus tard. Autour de la boutique de forge, du sous-sol de l'église et du restaurant de la mère Bonsaint, la population fort remuante de Saint-Paul-de-la-Croix écrit sa petite histoire bien à elle... 
On se croirait en sécurité, à l'abri de l'agitation et de l'inquiétude dans ce monde bien en place où l'on sait exactement qui est qui et qui fait quoi: on sait qu'Hermel le paralytique, c'est le fils de la mère Bonsaint, celle-là même qui tient restaurant et pension; on sait que sa terre jouxte celle d'Antoine Côté-de-la-côte, pieux homme qui fournit au Bon Dieu, depuis des années, une abondante progéniture qui remplit d'aise le curé Levesque, mais qui le poussera à vendre cette même terre à Eusèbe Corbin, habitant ambitieux de faire concurrence à Pamphile Belzile, marchand cossu et trop prospère; ce qui ferait bien l'affaire du forgeron Émile Thibault, qui trouve qu'un peu de changement ne ferait pas de tort, ce en quoi sa femme Maria, commère attitrée du village, ne lui donnera pas tort, pour une fois; sans parler des intérêts làdedans de la veuve Rose-Alma April, de ce bon-à-rien de Nel Gamache, du taxi Simon-à-Orgèse qui y trouvera bien son compte, et de Catherine, la fille de Bertrand Bossé, ancien maire et défunt mari de la veuve Aimée...

Mais sous des dehors paisibles, il se passe bien des choses à Saint-Paul-de-la-Croix, des événements anodins et d'autres bien plus graves. C'est par exemple l'arrivée de Louis Mortan, agent d'assurances et Français de surcroît; c'est l'accident tragique d'Anatole Thibault; c'est le départ d'Hermel pour le petit séminaire de Rimouski; c'est le mariage-surprise d'Eusèbe Corbin, l'incendie louche du magasin général; sous des dehors sages, la vie insoupçonnée des villageois: chantage, débauche, jalousies, meurtre... Et c'est surtout l'histoire d'Aimée Bossé, veuve bien jeune et encore bien fraîche pour se résigner à la sécheresse et à la solitude. Au fil des pages, la révolte d'Aimée gronde de plus en plus fort, au rythme même de la folie qui s'empare d'elle; folie, révolte contre les hommes profiteurs, la religion inflexible, les préjugés tenaces, contre toute hypocrisie, enfin... Révolte qui fait danser Aimée, toute seule, le soir, malgré les ragots des âmes bien-pensantes; à l'image d'une autre qui aimait trop la vie, à l'image de Rose Latulippe, Aimée joue avec le feu, danse avec le diable...

Le roman de Laurent Dubé, s'il ne plaira pas à tous, est en tout cas infiniment vivant. Sa construction en plusieurs petits 
tableaux de quelques pages lui assure un rythme rapide, anecdotique et léger. Damnée Aimée se lit sans douleur (enfin!), aussi bien calé dans son fauteuil favori qu'entre deux stations d'autobus (vous pouvez m'en croire!). Petit avertissement: voilà un roman qui s'apprivoise. L'on n'est pas séduit d'emblée par l'histoire; mais peu à peu, les personnages nous envahissent, s'attachent à nous et nous laissent plus facilement refermer le livre...

On peut bien sûr arguer que la vague de folklorisme à outrance nous a laissés saturés de notre "patrimoine terrien", et que nous sommes bien peu enclins à ouvrir "encore" un roman qui nous parle de nos origines villageoises. C'est un point de vue que je comprends très bien; et cependant il faudrait se garder de juger à l'avance et donner sa chance au coureur...

Le roman de Laurent Dubé ne m'a, quant à moi, vraiment déplu que lorsqu'il se propose de nous décrire les fantasmes d'Aimée:

Dans des rivières tièdes elle baignait son corps tourmenté et le sang coulant de ses mamelles rougissait les eaux de l'inlassable courant.

À d'autres moments, elle s'enfuyait dans la forêt pendant qu'on lui enfonçait des flèches dans le corps. (...) Sur le chemin du retour, elle rencontrait Bertrand Bossé qui la violait et continuait sa route avec Angéline Corbin... (p. 67)

Seigneur! Que d'auto-violence... Encore une qui rêve de se faire violer. Que direz-vous, d'ailleurs, lorsque vous apprendrez qu'Aimée se fera effectivement violenter? Que c'est bien ce qu'elle voulait, non? J'aurais tellement apprécié qu'Aimée se permette de beaux fantasmes originaux... D'accord, Aimée est malade, mais tout de même... Un peu d'imagination, que diable!

Je termine donc sur cette réserve qui ne découragera pas, je l'espère, votre éventuelle lecture (ce serait quand même dommage...). 
II y aurait eu, bien sûr, mille autres choses à dire...

Bon signe, non?

Françoise Daigle, UQAR 